University of Rhode Island

DigitalCommons@URI

Open Access Master's Theses

1993

\title{
Vocabulary Differences in Skilled and Less-Skilled Readers
}

Susan Loretta Curley

University of Rhode Island

Follow this and additional works at: https://digitalcommons.uri.edu/theses

\section{Recommended Citation}

Curley, Susan Loretta, "Vocabulary Differences in Skilled and Less-Skilled Readers" (1993). Open Access Master's Theses. Paper 1619.

https://digitalcommons.uri.edu/theses/1619

This Thesis is brought to you for free and open access by DigitalCommons@URI. It has been accepted for inclusion in Open Access Master's Theses by an authorized administrator of DigitalCommons@URI. For more information, please contact digitalcommons-group@uri.edu. 
VOCABULARY DIFFERENCES IN SKILLED AND LESS-SKILLED READERS

BY

SUSAN LORETTA CURLEY

A THESIS SUBMITTED IN PARTIAL FULFILLMENT OF THE REQUIREMENTS FOR THE DEGREE OF

MASTER OF ARTS

IN

PSYCHOLOGY

29743493
UNIVERSITY OF RHODE ISLAND

1993 
Abstract

School psychologists are confronted daily with the importance of reading ability for academic success. Illiteracy has been associated with drop out rates from school and with increased levels of welfare, unemployment and crime.

Given the importance of reading, questions of how to identify and assign remedial assistance to children who are not learning to read also becomes important to school psychologists, who play a primary role in this process. In recent years, assignment of remedial assistance has often depended on obtaining a discrepancy between scores on measures of reading achievement and of general cognitive ability. Vocabulary knowledge is often a key component of the evaluation of general ability. Yet, current literature suggests that estimates of vocabulary knowledge for poor readers may vary depending on the method of assessment employed.

In the present study, the correspondence between reading skills and several measures of vocabulary was evaluated. It was hypothesized that vocabulary measures with a phonological emphasis would be more sensitive to individual diferences in reading skill than would other vocabulary measures.

Skilled and less-skilled readers at the second- and fifth-grade level were identified using the Word Attack portion of the Woodcock Reading Mastery Test Revised. The Word Identification and Passage Comprehension subtests of the Woodcock Reading Mastery Test - Revised were also given. The relationship between these measures and several vocabulary measures was examined. The measures were the Peabody Picture Vocabulary Test - Revised, a variation of the Boston Naming Test, and the Vocabulary subtest from theWeschler Intelligence Scale for Children - Revised. The hypothesis that vocabulary measures with phonological demands would be more sensitive to reading group differences in vocabulary performance was supported. In second grade, skilled and less-skilled 
readers were comparable on all of the vocabulary measures except the version of the Boston Naming Test used, the only one requiring the production of a specific phonological label. In the fifth-grade sample, the less-skilled readers performed less well on all of the vocabulary measures, pointing to a widening gap in vocabulary knowledge between reading groups as children get older. These findings suggest that the pattern of association between reading skills and vocabulary measures changes over time. The implications of the results for assessment procedures used to allocate services for reading assistance are discussed. 
Table of Contents

Introduction 1

Methods 9

Results 14

Discussion 18

Appendix A 23

Appendix B 24

Bibliography 26 


\section{Introduction}

The central role of reading skill for both academic and career success is widely recognized. Illiteracy has been associated with increased levels of welfare, unemployment and crime (Adams, 1990; Kozol, 1987; Orton Dyslexic Society, 1986). Given the importance of reading ability, the questions of how to identify children who are having difficulty learning to read and how to assign remedial assistance to them also becomes important.

For more than a decade, educators and school psychologists have favored assigning remedial aid on the basis of a discrepancy between IQ and academic achievement. There are a number of ways to define a discrepancy (Shepard, 1980). One of the most common is simply to look for a significant

difference between scores on a standardized measure of cognitive ability and a standardized measure of achievement. Two issues need to be considered when such a discrepancy formula or score is used to assign aid. The first concerns the assessment of IQ: which cognitive abilities should be selected as most relevant for estimating an individual's intellectual ability? A second, related matter, is that in many cases reading disabilities stem from underlying language difficulties which may also affect the verbal skills assessed by IQ measures. Thus, the utility of both verbal and nonverbal measures in defining reading disability needs to be considered. In particular, phonological aspects of language processing have been found to be impaired in poor readers (e.g., Liberman \& Shankweiler,1985; Wagner \& Torgesen, 1987). Might poor readers therefore be expected to have lower performance on those verbal IQ measures which are more dependent on phonological processing? Consequently, for many children there may be a lack of discrepancy when comparing reading achievement and measures of verbal skills. It is likely that 
remedial aid could benefit these individuals, though their reading achievement and verbal skills are at corresponding levels.

In order to accurately assess reading disability, the relationship between the disability and the various measures used for assessment must be clearly understood. Vocabulary knowledge is a verbal construct frequently used in the evaluation of cognitive ability in relation to reading achievement, yet it is measured in a variety of ways that may tap different underlying verbal processes. The goal of the present study was to examine whether the association between performance on vocabulary tasks and reading skill differs depending on the age of subjects and on whether the vocabulary task stresses semantic or phonological processes.

Before describing the experimental goals and procedures for this study, a brief review of the prior evidence on the assessment of verbal and nonverbal IQ in relation to reading disability will be discussed. In addition, factors in the vocabulary ability of poor readers will be examined.

\section{Assessing 10}

The question of which cognitive abilities should be used in the assessment of reading disabilities has been debated repeatedly. Numerous, and often diametrically opposing, answers to this question have been offered.

Different answers to this question have been shown to result in different subgroups of children identified as disabled (Stanovich, 1991). Thus, it becomes important to determine which cognitive abilities are most relevant and accurate for defining reading disability.

A common recommendation in the literature on reading disability is that nonverbal, or performance, measures be used in assessing a discrepancy between IQ and reading achievement (see Stanovich, 1991, for discussion). This recommendation stems from the belief that a reading disability is an 
"unexpected" failure in relation to the other cognitive abilities. It is argued that since reading achievement depends on verbal skills, it may be "unfair" to use verbal cognitive abilities when attempting to assess a discrepancy. This reasoning led to the advocacy of the use of nonverbal abilities in assessment procedures.

The problem with this, as Stanovich (1991) states, is that verbal measures may be more relevant than nonverbal measures in assigning remedial assistance because they are more closely related to reading ability than are nonverbal measures. Stanovich's argument for the use of verbal measures in place of nonverbal IQ measures is supported by a large body of research linking reading ability to linguistic or verbal skills (e.g., Liberman \& Shankweiler, 1985; Perfetti, 1985; Stanovich, 1985; Vellutino, 1979; Wagner \& Torgesen, 1987). The logic of using nonverbal measures to assess reading disability when verbal measures are more closely linked to reading performance is thus somewhat tenuous. Hessler (1987) states, "using a nonverbal test of intelligence because an individual has better nonverbal cognitive abilities does not, of course, remove the importance of verbal processing and knowledge structures in academic achievement; it only obscures their importance and perhaps provides an unrealistic expectation for an individual's academic achievement" (p. 46). Since verbal measures are related to reading ability, and since they are effective in predicting academic outcomes it has been suggested that they be used in identifying reading disability rather than nonverbal measures (Stanovich, 1991). An alternative suggestion is that reading disability be define solely on the basis of reading deficits, specifically decoding deficits (Seigel, 1989). That is, Seigel proposes that all children who are struggling with letter-sound correspondances and non-word reading should receive assistance. 
Although the arguments for the use of verbal measures are strong, they fail to provide information on which verbal skills should be evaluated. In light of the multitude of methods available to assess verbal processes, this is an important issue to address. Even for vocabulary, often a central component in the assessment of $I Q$, there are a number of assessment techniques. Vocabulary can be examined with receptive or expressive measures. These tasks may have a semantic or phonological focus. If an individual's performance on all vocabulary measures is closely related, the choice of assessment instrument may not be critical. If, on the other hand, the language deficits of poor readers are more specific, then a difference in performance might be expected depending on the choice of task. If the later is the case, then task selection might influence the magnitude of the discrepancy score. Thus, it is necessary to determine whether poor readers' performance on vocabulary measures varies depending on the particular vocabulary task utilized.

\section{Vocabulany Ability of Poor Readers}

A growing body of research suggests that reading-disabled children have a number of phonological processing difficulties. This finding has a number of implications related to the vocabulary acquisition of poor readers, as well as for the assessment of their vocabulary knowledge. In general, poor readers have been obsened to have lower vocabulary scores (e.g., Kail \& Leonard, 1986; Vellutino \& Scanlon, 1987). Vellutino and Scanlon (1987) noted that even when matched on nonverbal IQ performance, reading-disabled groups scored consistently lower than non-disabled groups on both productive and receptive vocabulary measures. Since they generally read less, lessskilled readers are hampered in vocabulary growth by reduced exposure to print (Hayes, 1988; Nagy \& Anderson, 1984; Pratt \& Brady, 1988; Stanovich, 1986). The issue is further complicated due to the so-called " Matthew effects", 
that is the idea that reading itself contributes to the development of cognitive abilities. The presence of Matthew effects weakens the distinction between aptitude and achievement. It thus correspondingly weakens the value of discrepancy formulas.

Furthermore, there may be underlying phonological problems for poor readers, leading to difficulty learning new words. Acquiring new words requires the accurate perception, storage and retrieval of words. When these skills are deficient, acquisition of new lexical items may be impaired (e.g., Aguiar \& Brady, 1991; Nelson \& Warrington, 1980). It may have significance for their vocabulary knowledge that poor readers have been documented to perform less well than skilled readers in each of these cognitive areas (Stanovich, $.1985)$.

Generally, poor readers do not perform as well as good readers on speech perception tasks. This may be due to problems in the initial encoding of speech in memory. The performance of poor readers is affected to a greater degree than that of good readers on difficult encoding tasks (e.g., Brady, 1986). For example, Brady et al. (1983) noted that poor readers made significantly more errors than good readers when listening to speech sounds embedded in noise. However, the two groups did not differ in the accuracy of their perception of nonspeech sounds. The authors hypothesized that poor readers are limited in their ability to encode verbal information in verbal working memory.

Just as poor readers have been observed to have difficulty in the perception of verbal material, they have also been shown to have deficits in the short-term recall of verbal information (see Wagner \& Torgesen, 1987;

Stanovich, 1985 for reviews). Since verbal working memory is hypothesized to be a limited capacity system, difficulty encoding information may hamper the retention processes of less-skilled readers (Brady,1986). Further, if the 
information is retained less well in verbal working memory, this also may have consequences for long-term storage (Stanovich,1985). Thus deficits in encoding and working memory could affect the vocabulary knowledge of lessskilled readers. Compatible with this line of reasoning, less-skilled readers appear to have inaccurate phonological designations for words placed in the lexicon (Katz, 1986).

The ability of poor readers to access words from the lexicon has also been found to be impaired. Poor readers make more errors retrieving phonologically complex labels (Catts, 1986). Even when receptive knowledge of vocabulary is controlled for, differences between good and poor readers have been noted in retrieving phonological labels for visual stimuli (e.g., Denckla \& Rudel, 1976; Katz,1986; Snowling et al.,1988). These errors may arise in the retrieval of words from the lexicon, from verbal working memory, or from both.

The phonological processing deficits poor readers demonstrate in speech perception, working memory, and lexical access have a number of implications for vocabulary development. With this in mind it might be anticipated that poor readers would have lower vocabulary knowledge scores, particularly on those measures that tax areas of phonological processing. This pattern has been observed (Vellutino \& Scanlon, 1980). As noted earlier, vocabulary differences between children who are reading disabled and their normally achieving peers are frequently obtained. Reading disabled children perform less well than peers on productive and receptive vocabulary measures, even when matched on IQ (Kail \& Leonard, 1986; Vellutino \& Scanlon, 1987).

In a recent study, Aguiar and Brady (1991) aurally presented nonsense words to fourth grade students, who were then taught definitions for each of the 
nonsense words. The students were divided into groups consisting of skilled and less-skilled readers. Less-skilled readers had more difficulty acquiring the phonetic information for new words than did skilled readers, however there was no difference in ability to provide definitions for the newly acquired words. Skilled and less-skilled readers appear to differ in the phonological processes related to vocabulary acquisition and knowledge, rather than in the semantic aspects. Nonetheless, it may be that poor readers need to devote a greater portion of cognitive resources to retain the sound structure of words which may, in turn, leave fewer cognitive resources for learning the meanings of words. In other words, phonological difficulties may impact upon higher cognitive processes (Stanovich, 1986).

Vellutino and Scanlon (1987) also examined the differences in the vocabularies of good and poor readers at the second and sixth grade levels. The students' performance on the Wechsler Intelligence Scale for Children Revised (WISC-R) verbal IQ, the WISC-R performance IQ, the WISC-R similarities subtest, the WISC-R vocabulary subtest, the Peabody Picture Vocabulary Test (PPVT-R), and tests of oral reading, as well as decoding skill, were compared. The younger poor readers displayed deficits on the oral reading tasks and on the decoding task but performed within the average range on the vocabulary and similarities subtests, each of which relies on semantic knowledge. Older poor readers displayed deficits in decoding ability and on the semantic vocabulary measures. Vellutino and Scanlon suggest that the older poor readers with practice become better at decoding skills, but lose ground in acquiring verbal definitions of words, perhaps due to longstanding phonological deficits.

The research conducted by Aguiar and Brady (1991), as well as by Vellutino and Scanlon (1987), suggests that differences in the phonological 
aspects of vocabulary knowledge may differentiate good and poor readers better than semantic differences. Vocabulary measures with a phonological component might more accurately identify poor readers or children at risk for becoming poor readers than measures which focus on semantic content. In a preliminary study, Snowling, Van Wagtendonk, and Stafford (1988) demonstrated that children identified as dyslexic performed as well as nondyslexic children when asked to point to pictures of words. This task taps conceptual knowledge of words. The same children performed significantly worse when asked to name pictures, a task requiring phonological information. Though these findings were obtained with a fairly small number of subjects ( $n=$ $33)$, they suggest that dyslexic children do perform differently on vocabulary measures that emphasize different components of word knowledge.

The goals of the present study were to confirm and synthesize the findings reported by Snowling et al. (1988) and by Vellutino and Scanlon (1987). First, the study investigated whether poor readers were impaired more on phonological measures of vocabulary than on semantic tasks. It was predicted that poor readers would show more impairment on phonological tasks. Second, using both younger (second grade) and older (fifth grade) children, the study examined whether older poor readers have semantic deficits in vocabulary knowledge as well as phonological difficulties. It was also predicted that as a result of phonological difficulties and reduced reading experience, older poor readers would display both phonological and semantic deficits. The results of this study provide information concerning the associations between aspects of vocabulary knowledge and reading ability, and age related changes in the patterns of association. This information may prove valuable in understanding the relationship between verbal portions of cognitive tests and reading achievement. 


\section{Method}

\section{Subjects}

The participants were 25 skilled and 21 less-skilled readers from the second grade, as well as 22 skilled and 19 less-skilled readers from the fifth grade. All participants were drawn from a school system in Rhode Island or a comparable school system in Connecticut. Both school systems that agreed to be part of the study were composed primarily of white, middle-class children. This population was chosen to minimize differences in vocabulary exposure at home.

Reading group placement, for the purposes of statistical analysis, was determined primarily by the Word Attack subtest from the Woodcock Reading Mastery test. This is a measure of decoding skill based on ability to read pseudowords. Although group placement was based on Word Attack scores, to ensure that subjects were appropriately placed scores on both Word Attack and Word Identification had to be consistent. That is, participants were required to score above the mean on both measures to be included in the skilled groups or below the mean on both measures to be included in the lessskilled group. Participants whose scores were not consistent on these measures were excluded from the study. To be included in the skilled reading groups, a grade-based standard score of at least 105 was required, while subjects in the less-skilled reading groups obtained grade-based standard scores of 95 or less. In addition, only children who fell within two standard deviations above, or one standard deviation below, the norm on the Peabody Picture Vocabulary Test -Revised (Dunn \& Dunn, 1981) were included in the study. These criteria were imposed to ensure that subjects would fall roughly in the average range of intelligence and would demonstrate a consistent performance across reading measures. Finally, because vocabulary gains are 
associated with age, participants had to be between 7 years, 0 months and 9 years, 0 months in second grade and between 10 years, 0 months and 12 years, 0 months in fifth grade so that reading group comparisons were based on children of the same age. An additional sixty-five participants did not meet these criteria and were neither tested further nor included in the analysis of the data. The four groups, once determined, were designated as second-grade less-skilled (2LS), as second-grade skilled (2SK), as fifth-grade less-skilled (5LS), as fifth-grade skilled (5SK). See Appendix A for descriptive statistics for the reading measures. The mean and standard deviation for age and month of school attendance was calculated for each of the groups. There was no significant difference in the age of skilled and less skilled readers in either grade (second: $F(1,86)=1.06, p=0.31$; fifth: $F(1,86)=0.12, p=0.73$ ). Because the group membership was determined by ability to read pseudowords and real words an ANOVA was calculated to determine whether the groups also differed in their ability to read and comprehend passages. Both second-grade and fifthgrade skilled readers demonstrated better passage comprehension than the same grade less-skilled readers (second: $F(1,44)=28.03, p<.05$; fifth: $F(1,39)=4.36, p<.05)$.

\section{Instruments}

Participants were tested on a nonverbal intelligence measure, on three reading measures and on three verbal tasks tapping different components of vocabulary skills.

1. Non-verbal intelligence measure

The Triangles subtest of the Kaufman Assessment Battery for Children (K-ABC) was used (Kaufman \& Kaufman, 1983). The triangles task requires subjects to arrange colored triangles in order to replicate presented patterns. This subtest has an average reliability coefficient of .76 and correlations of .63 (2nd grade) 
and .67 (5th grade) with the Mental Processing Composite of the K-ABC. The task is begun at a predetermined age appropriate item. A basal is obtained when the subject gets one item in a unit correct. The ceiling is reached at either the set stopping point for each age or when all items in a unit are failed, whichever comes first. However, if a subject is correct on all the items specified for his age range, testing continues until he fails an item. This task has a mean standard score of 10 and a standard deviation of 3. See Appendix A for reading group scores.

2. Reading measures:

(a) Woodcock Reading Mastery Test-Revised: Word Attack Subtest: The Word Attack subtest requires subjects to read phonetically regular nonsense words in order to assess decoding ability. Internal consistency reliability was determined on a large national sample by the test authors using split-half procedures corrected with the Spearman-Brown formula. The split/half coefficients are between .89 and .94 . Content validity was determined by independent curriculum experts for test development. When compared to the Word Attack subtest of the Woodcock-Johnson Achievement Battery the concurrent validity coefficient is .90 . Basal level for this task is determined by getting all items within a unit (e.g., a block of items) correct. The ceiling is defined by the point in which the subject fails all items in a unit. The mean standard score is 100 with a standard deviation of 15.

(b) Woodcock Readina Mastery Test-Revised: Word Identification Subtest: The Word Identification subtest requires subjects to read real words in order to assess decoding ability. Internal consistency reliability was determined by the test authors with the same procedure utilized for the Word Attack Subtest. The split-half coefficients were determined by the test authors to fall within an acceptable range (e.g. .91 for fifth grade). Content validity was determined by 
independent curriculum experts for test development. This subtest demonstrated acceptable concurrent validity when compared to the Word Identification subtest of the Woodcock-Johnson Achievement Battery (.83). Basal and ceiling levels are determined as in the Word Attack subtest. Again, the mean standard score is 100 with a standard deviation of 15 .

(b) Woodcock Readina Mastery Test-Revised: Passage Comprehension Subtest: Passage Comprehension requires subjects to read brief passages and, when done, to provide one missing word. Procedures for determining internal consistency reliability, content validity, and concurrent validity followed the procedures utilized for the Word Attack subtest. The split/half coefficients are between .90 and .96 . Basal and ceiling levels are determined as in the Word Attack subtest. The mean standard score is 100 with a standard deviation of 15.

3. Vocabulary measures

(a) Peabody Picture Vocabulary Test-Revised (Dunn \& Dunn, 1981): The Peabody Picture Vocabulary Test-Revised (PPVT-R) requires subjects to point to the picture that, out of a choice of four, best represents a word spoken by the examiner. The median test-retest reliability coefficient of this test is .82 . The PPVT-R has a correlation of .69 with the WISC-R Vocabulary subtest. The basal is reached when a subject responds to 6 consectutive items correctly. Testing is discontinued when a subject fails 6 of 8 items. The mean standard score for this task is 100 with a standard deviation of 15.

(b) The Vocabulary subtest of the Wechsler Intelligence Scales for ChildrenRevised (WISC-R) (Wechsler, 1974): The Vocabulary subtest entails providing verbal definitions for words spoken by the examiner. It has an average reliability coefficient of .86 and a correlation of .89 with the verbal scale of the WISC-R. Basal for a subject is established when the subject achieves two 
consecutive perfect scores (two points out of a possible two points). Testing is discontinued after 5 consecutive failures. This task has a mean standard score of 10 and a standard deviation of 3 .

(c) Naming measure

The author devised a naming task based on the Children's version of the Boston Naming Test developed by Maryanne Wolfe (See Appendix B for a copy of the measure). The first phase of this task required subjects to name the line drawings of the Boston Naming Test. After the subject incorrectly named six of eight consecutive pictures, the first phase was terminated and phase two was begun. In the second phase subjects were presented once more with the pictures they had failed in phase one to identify correctly. This time four alternative choices were read and subjects were asked to choose the correct alternative. One of these choices was phonologically similar to the target word and one was semantically similar. This procedure provides an assessment of the receptive knowledge of the words while it also allows a measure of the phonological accuracy of the individual's lexical representation for a word. The score used was the subject's percent correct of the possible total of 60 (BNT60).

\section{Procedure}

After the University's Institutional Review Board's approval was obtained, school superintendents, principals, and teachers were contacted and asked to participate in the study. Consent was then obtained from parents. Each child was tested in two sessions. All measures were administered individually. During the initial session, the Word Attack and then the Word Identification portions of the Woodcock Reading Mastery Test were administered first. Performance on both of these measures was tape recorded so that the scoring could be checked. These measures were followed by the nonverbal measure, 
Triangles. Finally, each child was given the Peabody Picture Vocabulary TestRevised. The first session lasted approximately 30 to 45 minutes. Due to time constraints, ten children were not able to take the PPVT-R in the first session. These children participated in an additional brief session in order to complete the PPVT-R.

In the second session, each child who met the criteria for further participation, as noted earlier, completed the remaining measures. The Vocabulary subtest of the WISC-R was administered first. This was followed by the naming measure. The last measure given was the Passage Comprehension subtest of the Woodcock Reading Mastery Test. The second testing session took between 45 and 60 minutes. After the conclusion of each session, the children were offered their choice of a sticker or a baseball card and were asked if they had any questions.

\section{Results}

The means and standard deviations of all vocabulary scores (WISC-R Vocabulary, PPVT-R, and BNT-60) were calculated for each of the four groups (See Table 1).

Table1

Means and Standard Deviations of the Vocabulary Measures Second-Grade Fitth-Grade

$\begin{array}{lllll}\text { Variable } & \text { Less-skilled } & \text { Skilled } & \text { Less-skilled } & \text { Skilled } \\ \text { Vocabulary } & 21.35(6.69) & 24.16(5.24) & 33.27(6.54) & 38.37(5.08) \\ \text { PPVT-R } & 92.67(10.85) & 95.88(8.41) & 114.17(10.83) & 120.05(6.67) \\ \text { BNT-60 } & 31.42(7.12) & 38.88(6.11) & 45.00(6.81) & 49.47(6.74)\end{array}$

Because school experience, age, and non-verbal ability have all been associated with vocabulary knowledge, these variables were included in the descriptive statistics and in the analyses to determine whether they differed 
systematically across groups. Correlations among the vocabulary scores were calculated (See Table 2).

Table 2

Correlation Matrix for Vocabulany Measures

Vocabulary PPVT-R BNT-60

Vocabulary $\quad 1.00$

$\begin{array}{lll}\text { PPVT-R } & 0.79 & 1.00\end{array}$

$\begin{array}{llll}\text { BNT-60 } & 0.76 & 0.79 & 1.00\end{array}$

Two MANOVAs were used to determine whether the reading groups differed significantly on the vocabulary measures. Because this study was cross-sectional in nature, comparability of the second- and fifth-grade groups was not certain. Thus, the decision was made to utilize separate MANOVAs for each grade. The first MANOVA examined the differences between secondgrade skilled and second-grade less-skilled readers on the vocabulary measures. The second MANOVA examined whether or not the skilled and less-skilled fifth-grade subjects differed on the vocabulary measures.

In second grade, the MANOVA indicated that there was a significant difference between the reading groups, $F(3,42)=5.39, p=0.003$. According to follow-up ANOVAs, skilled readers performed significantly better than lessskilled readers on the Boston Naming Test, a productive vocabulary task requiring one word responses, BNT-60, $F(1,44)=13.67, p=0.001$. However, there was no significant difference between the two groups on WISC-R Vocabulary which, although a productive task, allows subjects to formulate definitions in their own words, thus reducing the specific phonological demands, $F(1,44)=2.55, p=0.12$, nor did the skilled and less-skilled readers 
differ significantly on the receptive vocabulary measure, the PPVT-R, $F(1,44)=1.28, p=0.26$.

Skilled second-grade readers also scored significantly higher on Triangles than the less-skilled second grade readers did, $F(1,44)=4.31, p<.05$. This suggests that in second grade this group of skilled readers may have greater non-verbal cognitive ability than the less-skilled readers in the same grade. In order to control for nonverbal IQ, a MANCOVA was calculated for the second grade subjects. Performance on Triangles was used as the covariate. The pattern of results was the same. The overall MANCOVA demonstrated a significant difference between the skilled and less-skilled readers, $F(3,41)=4.12, p=0.01$. In the follow up tests, the skilled and less-skilled readers differed significantly on the BNT-60, $F(1,43)=10.26, p=0.003$. And again, the groups did not differ significantly on Vocabulary, $F(1,43)=0.63, p=0.43$, or on PPVT-R scores, $F(1,43)=0.62, p=0.44$.

In fifth grade the pattern of results shifted. In the overall MANOVA, a trend for skilled readers to perform better than less-skilled readers on the vocabulary tasks was visible, $F(3,37)=2.74, p=0.056$. This trend is just short of the significance level, perhaps due to the small number of participants used. Follow-up ANOVAs indicated that skilled and less-skilled readers differed significantly on all vocabulary measures. Skilled readers obtained significantly higher scores on all of the vocabulary tasks: Vocabulary, $F(1,39)=7.58$, $p=0.009 ;$ PPVT-R, $F(1,39)=4.27, p=0.04 ; B N T-60, F(1,39)=6.11, p=0.02$. These lower vocabulary scores were observed despite the fact that there was no significant difference between the groups on the Triangles task, $F(1,39)=160$, $p=0.21$, in time of testing, $F(1,39)=0.86, p=0.36$, or in age at the time of the first testing session, $F(1,39)=0.12, p=0.73$. 
A power analysis $\left(\mathrm{Eta}^{2}\right)$ was then conducted in order to determine the proportion of variance in reading group accounted for by each of the vocabulary measures at each grade (See Table 3). The power analysis indicated that the Boston Naming Test accounted for a fair amount of the variance at both ages. Therefore, a step down analysis was conducted. This analysis revealed that the BNT-60 significantly differentiated skilled and lessskilled readers at both second-grade, $F(1,45)=12.93, p=0.001$, and at fifthgrade, $F(1,39)=6.11, p=0.02$. When the effect of the BNT was removed through covariation, the groups did not differ significantly on the vocabulary measure at second grade, $F(1,44)=0.011, p=0.92$, or at fitth grade, $F(1,38)=2.01, p=0.16$. No significant difference was found between skilled and less-skilled readers on the PPVT-R when both BNT-60 and Vocabulary were covaried out of the analysis for second grade; $F(1,43)=2.36, p=0.13$, or for fifth grade; $F(1,37)=0.14, p=0.71$.

Table 3

Proportion of Variance Accounted for by Vocabulary Measures

Measures Second-Grade Fifth-Grade

$\begin{array}{lll}\text { Vocabulary } & 0.05 & 0.16\end{array}$

PPVT-R

0.03

0.09

BNT-60

0.26

0.1

The outcome of the power analysis and the stepdown analysis confirm the shared variance between the vocabulary measures and indicates that the critical difference between reading group is adequately captured by the vocabulary task requiring retrieval of specific phonological sequences, that is the version of the BNT used in this study. 


\section{Discussion}

The results of the present study support the hypothesis that less-skilled readers have weaker vocabulary skills, particularly for tasks tapping the phonological content of words. Both second- and fifth-grade less-skilled readers obtained significantly fewer correct responses than skilled readers on the task with the greatest phonological demands - the children's version of the Boston Naming Test. As predicted, older poor readers displayed more widespread vocabulary deficits. In addition to difficulties with the productive vocabulary task (BNT), they did significantly less well than skilled readers on the vocabulary subtest of the WISC-R, a task which relies on semantic knowledge, and on the PPVT-R, a receptive task which minimizes phonological demands. In general it was found that the association between performance on vocabulary tasks and reading skill differs depending on the grade of a child and on whether the vocabulary task emphasizes semantic or phonological processes.

These results extend the 1988 findings of Snowling, Van Wagtendonk, and Stafford. Snowling and her colleagues reported that fifth-grade dyslexic children display differences on vocabulary tasks, depending on which component of word knowledge is required in the task. In that study fifth-grade dyslexic children did as well as nondyslexic children on a task examining conceptual knowledge of words, but significantly worse on a vocabulary task with phonological demands. The present study supports Snowling, Van Wagtendonk, and Stafford's work using a large number of second-grade children who were not identified as having special needs. Second-grade, lessskilled readers did less well on the more phonologically demanding task than they did on a task that stressed conceptual knowledge while minimizing 
phonological demands. However, unlike the results of Snowling and her colleagues (1988), the present study also found differences between the skilled and less-skilled fifth-grade readers on their semantic knowledge of words. This inconsistency may stem from a number of differences between the two studies. The present experiment had a larger sample of participants and utilized a more comprehensive semantic measure, thus it may have been more sensitive to group differences. Additionally, the children in Snowling et al.'s sample were receiving remedial assistance which may have affected their performance.

The common finding that less-skilled readers did less well on the more phonologically demanding task than they did on a task that stressed conceptual knowledge while minimizing phonological demands may be related to the fact that such readers have been shown to demonstrate deficits in the phonological processes of word perception, storage, and retrieval (see Wagner \& Torgesen, 1987 , for review). All of these processes are involved in the acquisition of new words (Aguiar \& Brady, 1991). Increasing the phonological demands of vocabulary tests may show impairments in these underlying processes more clearly.

A further question that has been examined is whether less-skilled readers of different ages show different patterns of vocabulary performance. Vellutino and Scanlon (1987) found that younger poor readers performed in the average range on tasks that are primarily semantic (e.g. WISC-R Vocabulary) in that they do not require a specific word answer in order to be considered correct, while older poor readers did display deficits on this kind of measure. Vellutino and Scanion attribute these changes to the fact that older poor readers do not acquire the meaning of new words as rapidly as good readers, due in part to their difficulties with phonological processing. A further impediment to vocabulary development may stem from the reduced lack of 
exposure that poor readers have to text (Stanovich, West, \& Cunningham, 1991).

In the present study, using both receptive and productive measures of vocabulary, a similar pattern of results was obtained. The outcome demonstrated that a productive measure, particularly one targeting specific phonological forms, was sensitive to reading-related vocabulary differences, as Snowling, Van Wagtendonk, and Stafford (1988) found. Here, the productive task (i.e., BNT-60) was also found to distinguish between skilled and lessskilled readers in the second grade. In addition, he results supported, with a productive measure, the likelihood that there is a developmental change in performance on vocabulary tasks, such as the one reported by Vellutino and Scanion (1987). As described earlier these authors obtained comparable performance on vocabulary tasks in younger children (second graders) who differed in reading ability, but inferior vocabulary performance was observed in less-skilled children in the sixth grade. This study duplicates their finding with older children, but as already noted, did find vocabulary differences between younger skilled and less-skilled readers when a specific phonological label had to be produced. The present study adds to the evidence that vocabulary deficits in poor readers increase as they get older. However, since the design of the study is not longitudinal, the results must be interpreted with caution. Yet the selection criteria employed and the use of standard scores for the reading measures provides some assurance that the second- and fifth-grade groups are comparable.

The shifting pattern of association between reading skills and vocabulary knowledge indicated in the present study poses problems for the accurate determination of the cognitive ability of children with reading difficulties. Not only do less-skilled readers perform variably on tasks that emphasize different 
aspects of word knowledge, but their performance on such tasks appears to changes over time. The results obtained here suggest that younger poor readers are more likely to display a discrepancy between reading skill and vocabulary knowledge than are older poor readers. That is, when a child is young, reading difficulty may be evident while achievement on vocabulary tasks that tap semantic knowledge appears to be age appropriate. Vocabulary knowledge in younger children may come more from frequent home and school experiences that are more likely common to all children. Older children may depend more on reading material for increases in word knowledge, which would put less-skilled readers at a disadvantage (Stanovich, West, \& Cunningham, 1991). In addition, the difficulty with word retrieval, suggested by problems on the Boston Naming Test, also points to subtle phonological problems that may impact on vocabulary acquisition (Aquiar \& Brady, 1991; Gathercole, Wilis \& Baddeley, 1991). In short, older students may have more pervasive vocabulary deficits both because of underlying phonological limitations and because of less exposure to new words through reading.

The present results, indicating that less-skilled readers may do better on certain vocabulary measures and that performance on vocabulary measures may be different at different ages raises questions about the use of vocabulary measures in the process of determination of eligibility for reading assistance. Unfortunately, as discussed in the introduction, the current widespread use of discrepancy scores entails the inclusion of vocabulary measures in the process for the determination of eligibility. This is a problem if, for example, it is required to show a relative discrepancy between reading level and level of aptitude. Given the results of this study such a discrepancy is more likely to be found for young children. Thus, older children needing remedial assistance may not be identified in a timely fashion. 
Just as a pattern of increasing evidence for vocabulary deficits appears over time, a pattern of increasing deficits in other areas that require verbal skills might also appear. Since measurement of verbal skills is a main component many tools used in cognitive assessments (e.g. the verbal scale of the Wechsler Scales), this is an important possibility to explore. Vellutino and Scanlon's 1987 study examined this possibility with the Similarities subtest of the Weschler Intelligence Scale for Children-Revised. This subtest, like the Vocabulary subtest, relies on conceptual understanding of words. The authors noted that a discrepancy between reading skill and achievement on the verbal scale is less likely to occur with older poor readers. Both the reading skills of older poor readers and their performance on the verbal scales were depressed. The present study provides further support for the possibility that reading ability and performance on other verbal tasks are inter-related. Stanovich (1986) hypothesizes that this relationship may be based on "Matthew effects". As noted in the introduction, these effects refer to the idea that the development of cognitive abilities stems in part from reading experience per se.

Recent research (Robertson,1993) indicated that a similar lack of discrepancy between reading skills and performance on verbal tasks is found in poor readers from a lower socio-economic background. The use of discrepancy scores may not then be the best method of determining eligibility for reading remediation either for older children or for children of low socio-economic status. Problems such as these have led some authors, such as Siegel (1989), to suggest that remedial reading assistance be assigned on the basis of nonword reading and on difficulties with sound-letter correspondences, rather than on discrepancy formulas, to ensure that all who may benefit from remedial aid receive it. 
Appendix A

Descriptive Statistics for Second and Fifth-Grade Reading Groups for Age, Time of Testing, Reading Skill

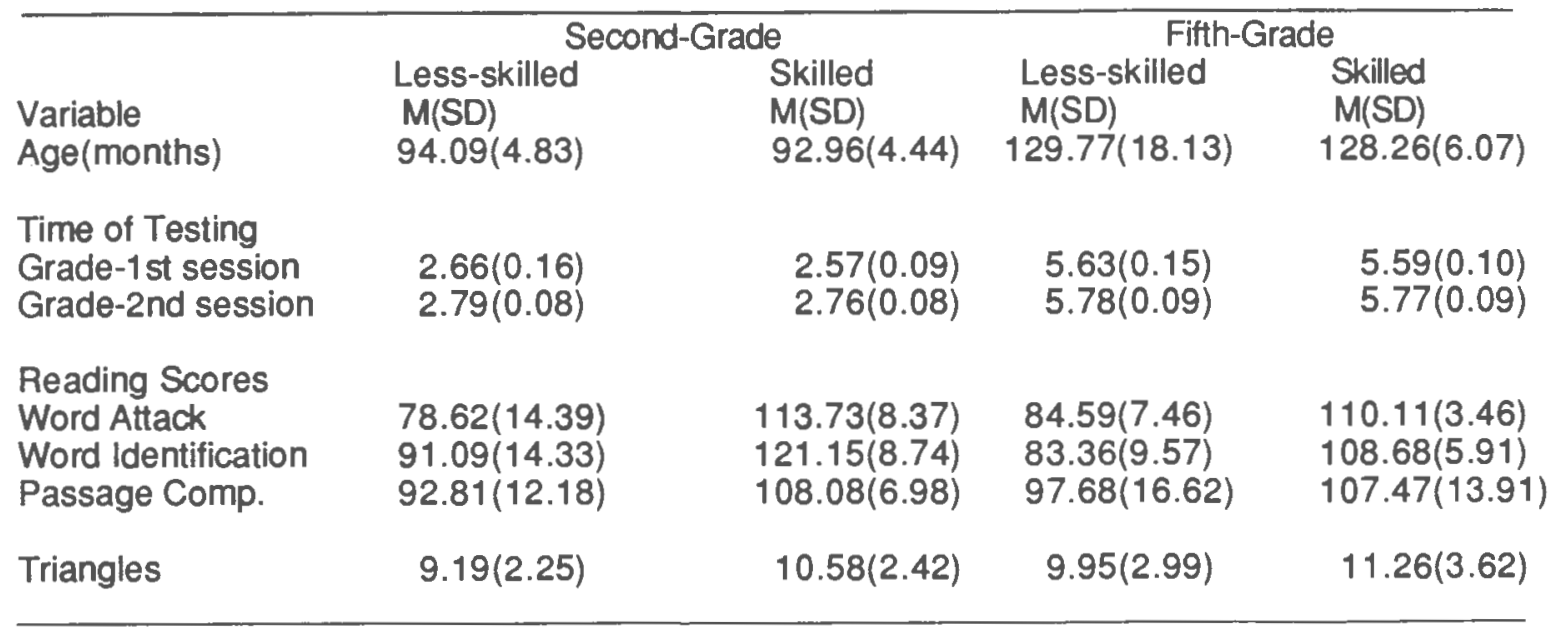


Appendix B

Boston Naming Test Protocol

NAME:

AGE:

Boston Naming Test

1.

2.

3.

4.

5.

6.

7.

8.

9.

10

11

12 ,

13.

14.

15.

16.

17.

18.

19.

20.

21.

22.

23.

24.

25.

26.

27.

28.

29.

sleeper

tree

pen

hose

whittle

tools

rake

flower

knife

tuba

helicopter

sweeper

fish

marshmallow

triangle

bike

desert

halloween

snakes

busstop

racquet

caterpillar

tornado

horsefish

dark

canoe

globe

reef

dam

$\begin{array}{lll}\text { bet } & \text { table } & \text { bed } \\ \text { leaf } & \text { treat } & \text { broccoli } \\ \text { stencil } & \text { stick } & \text { pencil } \\ \text { box } & \text { house } & \text { building } \\ \text { cannon } & \text { whistle } & \text { toy } \\ \text { scissors } & \text { spoons } & \text { sisters } \\ \text { comb } & \text { brush } & \text { cone } \\ \text { plant } & \text { fowler } & \text { pinwheel } \\ \text { sower } & \text { hammer } & \text { saw } \\ \text { toothbrush } & \text { comb } & \text { brush } \\ \text { airplane } & \text { hoptacopter } & \text { wasp } \\ \text { brush } & \text { broom } & \text { mop } \\ \text { platypus } & \text { octopus } & \text { spider } \\ \text { lamp } & \text { plant } & \text { mushroom } \\ \text { hammer } & \text { coat } & \text { hanger } \\ \text { wheelchair } & \text { wheeler } & \text { hospital } \\ \text { camel } & \text { horse } & \text { cambell } \\ \text { mask } & \text { macs } & \text { face } \\ \text { prencil } & \text { cookies } & \text { pretzel } \\ \text { bench } & \text { stool } & \text { beach } \\ \text { tennis } & \text { rocket } & \text { fly swatter } \\ \text { snail } & \text { snake } & \text { bug } \\ \text { mountain } & \text { earthquake } & \text { volcano } \\ \text { seahorse } & \text { dragon } & \text { starfish } \\ \text { game } & \text { dart } & \text { carrot } \\ \text { paddle } & \text { canary } & \text { surfboard } \\ \text { world } & \text { glove } & \text { ball } \\ \text { wreath } & \text { Christmas } & \text { hat } \\ \text { beaver } & \text { beater } & \text { squirrel } \\ & & \\ & & \end{array}$


30.

31.

32.

33.

34.

35.

36.

37.

38.

39.

40.

41.

42.

43.

44.

45.

46.

47.

48.

49.

50.

51.

52.

53.

54.

55.

56.

57.

58.

59.

60. matchbook

rinosaurus

pine cone

turtle

sticks

dominoes

cactus

elevator

violin

net

knocker

helicop

heart-beater

temple

muzzle

myth

drainer

harpsichord

hanger

broccoli

tweezers

hinge

triped

scroll

tweezers

links

yoke

lattice

paint

protracter

counter $\begin{array}{ll}\text { hornica } & \text { whistle } \\ \text { dinosaur } & \text { hippopotamus }\end{array}$

thineceros

corn

ialoo

stools

dice

pine tree

zipper

harp

hammock

candle

seagull

earphones

pyramid

harness

unihorn

funnel

fan

loose

branch

circles

hatch

easel

script

tongs

lion

saddle

fence

mattette

arch

abyss acern

icehouse iglet

stilts

poles

blocks

donimoes

desert castle

escalater stairs

gate

heart

hammer sleeper

door bell locker

pelican bird

telescope stethoscope

mountain primitive

mask nuzzle

horse

unicorn

horn tunnel

accordion organ

rope

noose

asparagus tarragan

compost compass

lock

latch

trestle

camera

letter

paper towels

ice cube picker

thongs

sphinx

Egyptian

harness choke

planter trellis

amoeba pallette

ruler

programmer

window abacus 
Bibliography

Adams, M. J. (1990). Beginning to read: Thinking and learning about print. Boston: MIT Press.

Aguiar, L. \& Brady S. (1991). Vocabulary acquisition and reading ability. Beading and Writing, 4, 115-127.

Brady, S. (1986). Short-term memory, phonological processing, and reading ability. Annals of Dyslexia, 36, 138-153.

Brady S., Shankweiler, D., \& Mann, V. (1983). Speech perception and memory coding in relation to reading ability. Journal of Experimental Psychology. 35, 345-367.

Catts, H. (1986). Speech production/phonological deficits in reading disordered children. Journal of Learning Disabilities. 19, 504-508.

Denckla, M. B., \& Rudel R.G. (1976). Naming of object-drawings by dyslexic and other learning disabled children. Brain and Language, 3, 1-15.

Dunn, L. M. \& Dunn, L. M. (1981). Peabody Picture Vocabulary Test-Revised, Circle Pines, MN: American Guidance Services.

Gathercole, S. E., Willis, C. S. \& Baddeley, A. D.(1991), Differentiating phonological memory and awareness of rhyme: Reading and vocabulary development in children. British Journal of Psychology, 82, 387-406.

Hayes, D. P. (1988). Speaking and writing: Distinct patterns of word choice. Journal of Memory and Language, 27, 572-585.

Hessler, G. L. (1987). Educational issues surrounding severe discrepancy. Learning Disabilities Research, 3, 43-49.

Kail, R. \& Leonard, L. (1986). Word-finding abilities in language impaired children. ASHA Monographs, 25, Rockland, MD: American SpeechHearing-Language Association. 
Katz, R. (1986). Phonological Deficiencies in children with reading disability:

Evidence from an object-naming task. Coanition, 22, 225-257.

Kaufman, A.S. \& Kaufman N. L. (1983) Kaufman Assessment Battery for

Children Interpretive Manual. Circle Pines, Minnesota: American

Guidance Service.

Kozol, J. (1980). Erisoners of silence. New York: Continuum.

Liberman, I. Y. \& Shankweiler, D. (1985). Phonology and the problem of

learning to read and write. Remedial and Special Education, 6 , 8-17.

Nagy, W.E. \& Anderson, R. C. (1984). How many words are there in printed

school English? Reading Research Quarterly, 23, 304-330.

Nelson H. E.\& Warrington (1980). An investigation of memory functioning in dyslexic children. British Journal of Psychology, 71, 487-503.

Orton Dyslexic Society (1986). Some facts about illiteracy in America.

Perspectives on Dyslexia, 13(4), 1-13.

Perfetti, C. A. (1985). Reading ability, New York: Oxford University Press.

Pratt, A. C. \& Brady S. (1988). Relation of phonological awareness to reading disability in children and adults. Journal of Educational Psychology, 80(3), 319-323.

Robertson, K. (1993). Phonological Awareness in Kindergarten Children of Differing Socio-economic Status, unpublished thesis, University of Rhode Island, Kingston, Rhode Island.

Shepard, L. (1980). An evaluation of the regression discrepancy method for identifying children with learning disabilities. Journal of Special Education. 14. 79-91.

Siegel, L. S., (1989). IQ is irrelevant to the definition of learning disabilities. Journal of Learning Disabilities, 22, 469-478. 
Snowling, M., Van Wagtendonk B.,\& Stafford C. (1988). Object-naming deficits in developmental dyslexia. Journal of Research in Reading, 11(2),67-85.

Stanovich, K. E. (1991). Discrepancy definitions of reading disabilities: Has intelligence lead us astray? Beading Research Quarterly, 26, 7-29.

Stanovich, K. E. (1985). Explaining the variance in reading ability in terms of psychological processes: What have we learned? Annals of Dyslexia, 35 , 67-96.

Stanovich, K. E. (1986). Matthew effects in reading: Some consequences of individual differences in the acquisition of literacy. Reading Research Quarterly, 21, 360-407.

Stanovich, K. E., West, R. F., \& Cunningham, A. E. (1991). Beyond phonological processes: Print exposure and orthographic processing. In S. A. Brady and D. P. Shankweiler (Eds.), Phonological Processes in Literacy: A Iribute to Isabelle Liberman, (pp. 219-235). Hillsdale, New Jersey: Lawrence Erlbaum Associates.

Vellutino, F. R. (1979). Dyslexia: Theon and research. Cambridge, MA: MIT Press.

Vellutino, F. R. \& Scanlon, D. M. (1987). Linguistic coding and reading ability. In S. Rosenberg (Ed.), Advances in Psycholinquistics, (pp. 1-69). New York: Cambridge University Press.

Wagner, R. K. \& Torgesen, J. K. (1987). The nature of phonological processing and its causal role in the acquisition of reading skills. Psychological Bulletin, 101, 192-212.

Wechsler, D. (1974). Wechsler Intelligence Scale for Children-Revised Manual. San Antonio, Texas: The Psychological Corporation . 